\title{
Exploratory Evaluation of Co-produced Groups in a Community Psychiatry Organisation in England
}

\author{
Joy Thorneycroft ${ }^{1,2} \cdot$ David Dobel-Ober ${ }^{1}$
}

Received: 18 May 2015/Accepted: 29 June 2015/Published online: 8 July 2015

(C) Springer India Pvt. Ltd. 2015

\begin{abstract}
This study evaluated co-produced rehabilitative social groups in English community psychiatric services. It aimed to describe the experience and views of staff and service users involved in group planning and delivery. A convenience sample (four staff and three service users) took part in this qualitative study. Service user co-producers were current/previous patients of secondary psychiatric services. The groups pre-existed this evaluation and included creative writing, walking, glass-crafting and reading activities. Interviews were semi-structured and transcribed verbatim. Thematic analysis was carried out by the first author using NVivo10 (CQSR) and reviewed and discussed with the second author. Co-production improved self-esteem, empowerment and purpose, and enabled recovery for service user co-producers. Staff provided necessary support for people with ongoing mental health problems. Risks were limited and well managed. Future research could examine the experiences of group participants who were not involved in co-production, and how organisational infrastructure can encourage these groups.
\end{abstract}

Keywords Rehabilitation - Co-production · Community mental health $\cdot$ Social groups $\cdot$ Recovery

Joy Thorneycroft

thornjkd@aston.ac.uk

1 Research, Development, and Innovation Team, Trust HQ, St George's Hospital, South Staffordshire and Shropshire Healthcare NHS Foundation Trust, Corporation Street, Stafford ST16 3SR, UK

2 Present Address: Aston University, Birmingham, UK

\section{Introduction}

\section{Aims and Definition of Coproduction}

Co-production is defined as service providers and service users/carers working together to produce services [1]; $\mathrm{co}$ creation (the joint production of a service from its inception) and co-facilitation (where service users help facilitate, although they may not be involved in planning) are directly related terms [2]. In public services, there is increasing awareness of the value of user generated knowledge, and the need to provide more personal, collaborative services [2]. People can be recognised as assets [3] and not merely repositories of need or recipients of services [4]. Co-production can challenge process-driven service delivery and counteract a culture where needsbased working can lead to disempowerment of people and where commissioning systems and targets produce a narrowing of aims and public spending cuts [3].

Policy documents about co-production abound [1,3] but good quality research is scarce [2]. Co-produced services have included time banking [5], expert patient schemes [3], projects for those with head injuries and within secondary education [6] and reading groups for service users of community psychiatry [7].

\section{The Importance of Groups}

Experience of disconnection is common in those with mental health problems [8]. Social and social-cognitive difficulties may also precede illness [9]. The quality and frequency of social contacts are related to prognosis [10] and there is evidence that interacting with peers is beneficial [11, 12]. Group interaction may help to act against unhelpful behavioural avoidance [13]. A review of the 
literature [14] found that mutual help groups benefited those with chronic mental illness, anxiety and depression and bereavement; groups may compensate for deficiencies in people's natural support networks.

\section{Particular Benefits of Co-production of Groups}

There may be especial benefits for those who co-produce; the giving of help is associated with improved functioning [15]. Recovery encompasses an on-going process of learning to live with disability and gradually rebuilding a sense of purpose, agency and meaning in their life [16]. Making an impact on another's life can enhance one's sense of interpersonal competence from [17]. Several metathemes have been identified in relation to consumer-providers in mental health: facilitating others' recovery/interpersonal competence, facilitating recovery/personally relevant knowledge/social approval and personal growth [18]. The role of a service user producer/facilitator is a form of volunteering, for which there is evidence for health benefit [15].

There may be benefits to being a member of a co-produced group rather than a professional led one: patients may benefit from being exposed to people who have already recovered to some degree [19]. Theoretically, peers within groups act as competent role models, enabling reciprocal learning [20] and there is strong evidence from randomised and quasi-experimental studies for experiential learning in a co-produced group [17].

Services may also benefit from service user input; peer providers with experience with the mental health system may alter negative attitudes of mental health providers [17]. Groups with leaders who were consumers have been shown to have significantly higher longevity than those led by professionals [21].

\section{Risks and Drawbacks of Co-production}

Taking part in mental health groups can be seen as a way to avoid a "normal" population and encourage social avoidance [10]. Staff turnover can cause problems in the continuation of service; taking responsibilities could place too much stress on someone that is unwell; and as membership is self-selective, there may be lower levels of attendance from those that are difficult to reach [19]. Questions can also be raised about how new opportunities are identified, commissioned and financed [2].

\section{Research into Groups and Co-production}

Theories about group work are very well developed, but there is still a need for stronger evidence about outcomes and effectiveness [22]. This is also true of co-production in mental health services, although psychiatric care is often pragmatic and eclectic rather than theory driven [10]. Exclusion of contextual factors is an inherent part of the design of many randomised studies [22], but context is often paramount in groups and in the phenomenology of attendance [10]. Qualitative, evaluative studies can add to our knowledge about groups.

\section{Method}

This project is an exploratory evaluation of co-produced groups in a local Mental Health organisation in England (National Health Service Trust) that provides services for a 1.1 million population. Its aims were to describe the experience of service users and professionals involved in developing and delivering such groups, identify factors promoting or hindering development and identify outcomes for key stakeholders.

\section{Participants}

A convenience sample of five co-produced groups was identified within the Trust. Groups included various activities: book club, glass-making, walking, creative writing and a magazine group; the last two groups were delivered by the same people. These groups were identified following informal conversations with key professionals such as occupational therapists and day services providers. This was not a systematic approach and other co-produced groups are likely to exist within the organisation.

A service user and a professional involved in the coproduction of the groups were invited to take part in an interview. Professionals were asked to act as gate keepers and in one instance, it was felt inappropriate to approach a service user who was currently unwell. In all, 3 service users and 4 professionals were interviewed; the latter included a psychologist and 3 community support workers. All participants were adults (4 males and 3 female).

\section{Procedures}

Semi structured interviews were conducted by the authors. Interviews lasted approximately $1 \mathrm{~h}$. The interview schedule was developed following a review of the relevant literature and informal discussion with key personnel within the Trust; key areas discussed included the development of groups, roles of service users and professional, and the impact of groups on participants and co-producers. The project was reviewed by the Trust's Research \& Development Department and recorded on the evaluation register, in line with local governance. 


\section{Analyses}

Each interview was transcribed verbatim and entered into NVivo10 (@QSR), a software package designed to support qualitative data analysis. Thematic analysis was conducted by the first author [23, 24]; the process was then reviewed by the second author and further discussed conjointly.

\section{Findings}

\section{Co-production versus Co-facilitation}

Interviewees shared an understanding of the differences between co-production and co-facilitation. Co-facilitation was described as the non-essential involvement of service users in the delivery of group interventions, without involvement in planning.

Service user facilitation was seen to enhance the value of groups by promoting and facilitating engagement with other service users:

"A catalyst to engagement, rather than spoon feeding them." (Staff 2)

Co-production was seen as significantly different to cofacilitation: it implied the shared involvement of service users and professionals in initiating, planning and delivering group activities. The involvement of both service users and professionals was seen as indispensable, even though their roles might be different.

"It was a sort of shared responsibility, I gathered information that I knew I could access. The service user looked more at the routes." (Staff 4)

Service users indicated that they valued professional input, but the relationship with them was a partnership with a clear sense of equality. Professionals described service users as 'co-worker', with the group being a 'shared enterprise' and none of the partners having soleresponsibility.

\section{Initiating Groups}

Co-production implied the involvement of service users from the outset, but the initial identification of a need for service provision could emanate from either party. The whole process appeared to develop organically, rather than via a formal process.

One professional identified an activity as a service user's therapeutic need; together, they organised a new activity group:
"We could have talked about the need to make a change in this room and I would have drawn some nice diagrams on the board which would have made the point, but the lived experience of it and the kind of reality testing of that is far more valuable." (Staff 4)

Two other groups were initiated by professionals with service users introduced at the planning stage; input at this stage was also valued by professionals:

"She had a great idea which was connecting two sessions together, it was very clever, I did tell her that." (Staff 2)

In other cases, service users identified a need or a gap in services and sought professional support to initiate the groups:

"It felt like there wasn't a lot of things there for me. A lot of the groups were to do with basic functioning. That's not what I needed help with." (Service user 1)

\section{Recruiting and Involving Co-producers}

No formal process for identification or recruitment of coproducers was described. Recruitment of staff often resulted from informal discussions amongst the teams or services. Staff participation in each group could vary: for instance, weather was an issue for a walking group.

Likewise, identification of possible service user co-facilitators was not systematic. When service users had not initiated the group, staff approached people they believed would contribute positively to the group but would also benefit from taking part; they were able to identify people who otherwise may not have been recognised as assets or who were not aware of their own potential at this time. The process was not straight forward and involved professional judgement. Staff seemed to look for previous experience, existing skills or specific interest, but also the ability and willingness to take additional responsibilities.

"Her interest in creative writing, and also the fact that she does display this kind of natural leadership qualities; [...] she was someone who's perhaps ready to take these responsibilities." (Staff 2)

"Attitude and I guess anyone could do that if they had the right support, I mean what's important is that they bring an interest." (Staff 3)

It was also apparent that the process needed to be managed sensitively, because service users were not always prepared or ready to take an active role. 
"I've been rejected a few times, people have a look of terror, and you think well they are certainly not ready, or ask another time." (Staff 2)

The main barrier to service user involvement was a lack of confidence.

"If it isn't something that you've done before, it would be more difficult to believe that you could do it, because of my past I am more comfortable talking to professionals than maybe some other people" (Patient 1)

Members of each group could gradually and informally become co-facilitators.

"Someone will perhaps bring in a poem they really like, and talk about it and in a way that's co-facilitating." (Staff 2)

Eventually, co-facilitators could also become co-producers. This had been the case in two groups; one of the interviewees took part in the group for 12 months before taking an increasingly active role. It was suggested that people may feel safer stepping into an existing role rather than starting new groups.

Some groups included more than one service user coproducer. Although this was generally seen positively because it could reduce the pressure on each individual, it was also felt that involving too many people in the planning could lessen effectiveness.

\section{Benefits for all Service Users}

Some of the benefits described by interviewees related to all group participants rather than specifically to service users involved in co-production. Some of those key benefits did not relate directly to the co-produced nature of the groups; they included opportunities for socialisation and developing a sense of purpose, confidence and self-esteem.

"The socialisation and normalisation of it, that's a big thing. Because lots of people with mental health problems become very isolated, and sometimes their cognition, the way that their illness affects them can change how they interact with other people." (Service user 1)

"Having a purpose to leave the house, I think that is hugely beneficial. If you get stuck in that, you don't want to go out, you are too afraid to go out; if you have got a purpose it kind of lessens." (Service user 2)

Some groups also involved using and developing skills that could be used elsewhere, including in a professional context.
"I've looked into, because I've really enjoyed the magazine side of it, I've thought about joining sort of the local paper, freelance or something like that, because I do enjoy the writing side."(Service user 2)

Other benefits were directly related to the involvement of co-producing service users in each group. The active role of service users in the planning and delivery of interventions seemed to guarantee that service users' needs would remain in focus throughout each intervention. This was reflected in the pace and time scale of the book club for instance:

"We can have a book for 3 months, everybody in the group understands that you may be suffering from depression, your concentration span can be little." (Staff 1)

Co-production seemed to bring a sense of normality to the activities and promote feelings of empowerment; participants were encouraged and enabled to take an active role in the groups rather they be mere recipients of a service or an intervention.

"I can appreciate the value that service users have when they feel that they are part of something not that they are being done to, that they are part of it themselves." (Staff 1)

Interviewees also pointed out that the relationship between service user facilitators and other group members was different to that with staff; they felt that seeing someone who was further along in recovery was particularly helpful for participants and could provide a positive role model.

"If a service user is co-facilitating, you can sense an immediate comfort there really, for the other members, because on one level, you've got perhaps a figure of inspiration [...]. There's someone who can say, I was like you, only 6 months ago, I was just like you. Whereas if I say that, perhaps it's not as believable." (Staff 2)

"People have positive role models. Sometimes when you are down very low, you can't see a way out of the pit at all. I think it is useful to have people involved who are moving on." (Service user 1)

Although the role of service users was seen as essential within the process, the presence of professionals was also described as necessary; this presence ensured that appropriate boundaries were maintained and that all participants could feel safe. Professionals also shared responsibilities with service user co-producers, thus making sure they didn't feel undue pressure.

Professionals were able to act as a resource and a link with mental health teams. The co-produced nature of the 
groups seemed to promote a broader understanding of service users' longer term needs. Both service users and professionals interviewed indicated that it was important to allow participants to carry on taking part in groups even after having been discharged from mental health services; informal access to a professional with a good understanding of their background was seen as a safety net. This had allowed relapse to be recognised at a very early stage for at least one participant; intervention was provided before the situation reached crisis point.

\section{Benefits for Service User Co-producers}

One of the four groups had been initiated in order to meet the specific needs of a service user; in this case, co-facilitating was seen to have met a therapeutic need:

"This person kind of had a tendency to withdraw; [...] it was the antidote, it satisfied a need." (Staff 4)

More generally, all interviewees indicated that service user co-facilitators had benefited from feelings of empowerment, self-confidence and a regained sense of purpose. Cofacilitators had the opportunity to show and share specific interests and skills; feedback from other participants had a positive impact.

"[...] he's got interests, and he can share it, and that does anyone's psyche the world of good, [...]. Other people are listening to them. I think that that's such a wonderful psychological sort of reward." (Staff 3)

Being involved in a successful process, both in term of project management and creative achievement, helped with self-worth feelings.

"I would hope there is a sense of empowerment, that's what we are hoping for... that hopefully will create a buzz of achievement, and therefore raise selfesteem and confidence." (Staff 2)

Taking an active role and responsibilities in a relatively safe and controlled context was described as particularly helpful:

"I think that gradual getting used to responsibility again is a good thing, but not being thrown into the deep end." (Service user 1)

"I'd say that's a balance [...]; a little bit of pressure, or a little bit of responsibility can be very helpful can't it, and to get people outside of themselves, and connecting with others." (Staff 2)

In some cases, the practical aspect of co-facilitation was seen to replicate previous positive professional experience:
"They had both [...] had careers and lost their way, and lost a lot of confidence and I think just that little bit of responsibility, kick started them back into you know where they both are today." (Staff 1)

On the whole, co-facilitating groups seemed to help people move away from their service user status and regain a sense of normality.

"There has been an increase in my confidence, belief in myself; it's helped me to move on. So it's meant that I viewed myself as someone who can do things, rather than as just a burden, a sick person." (Service user 1)

The active presence of a professional also meant that service user co-producers could experience and benefit from groups like other participants when they chose to.

"Having a professional there is brilliant, because you can go and be a member if that is all you need to do.... I've always gone; there's been times I've been ill, and I haven't really needed to say that." (Service user 1)

\section{Benefits for Professionals and Services}

Co-production was seen by professionals as essential to group delivery not only because of the experience and insight service users could provide but also because of the additional capacity they brought to services.

Groups would not happen or have the same value without dual involvement: co-production ensures the needs of service users remain in focus at all time.

"There are some people who are degree level and there are some who struggle with grammar and things like that, and it's not always just because of their ability, it's often because of their illness. So it's insightful really to work with a service user, definitely, it gives me confidence really, that what I'm delivering is perhaps suitable." (Staff 2)

Professionals need to be prepared to run groups on their own if service user co-producers are unwell or are unable to attend; however, the regular involvement of service users was seen as essential to on-going group delivery. Coproducers bring more than their experience and insight as service users: they also increase capacity in services and make groups viable where services are otherwise underresourced.

"He makes the group run; I wouldn't have the same capacity without him. [...] You couldn't run the group without him”. (Staff 3) 


\section{Risks and Drawbacks}

Both staff and service users interviewed identified risks associated with co-production. The main concerns related to the stress and pressure of running groups, with the potential impact on the mental health of service user coproducers. Staff were all aware that taking responsibilities could have a negative impact on service users; they emphasised the need to support and not to overload them.

"I am conscious that she takes on too much and that then ultimately makes her [...] unwell again.” (Staff 1)

Professionals tried to allay potential pressure by reassuring co-producers that groups could carry on running without their presence.

"I hope [Name] knows that these groups are quite relaxed, that if she wasn't able to come or if she was ill then we would carry on." (Staff 2)

Service users also identified risks to their own mental health but such risks were outweighed by the potential benefits:

"Apart from the anxiety, after I get over that, I feel quite good that I have actually done it. But at first, when I first started doing it, I was terrible, I was having panic attacks and everything, so I'm getting better at dealing with people." (Service user 3 )

Professionals provided a safety net, thus allowing service users to take risks in a relatively safe and controlled environment.

"I can acknowledge that they're not very well or if they tell me, then I can either do what it is that day or liaise with their care co-ordinator so it's a link." (Staff 1)

Interviewees also identified potential confidentiality issues. The dynamic and changing nature of co-produced groups seemed to be reflected in the fact that none of the groups had formal ground rules. The constant presence of a professional seemed sufficient to deal with potential problems.

"If there were any issues they were dealt with on the spot." (Staff 4)

Interviewees indicated that risks were minimised because activities did not focus on personal situations or the mental health of participants; service user co-producers were not privy to any clinical information.

\section{Resources}

All groups included in this study required relatively little resources in terms of staffing and equipment or facilities.
Despite the low cost, specific budgets were not allocated to the projects and material resources were difficult to obtain; both service users and staff had to be creative, often relying on material gifts. Several interviewees indicated that a lack of coordination within and across services compounded the issue:

"I think there are little pockets of things, as I've been looking, I've gone round and asked people, and I've found things, but the individual pockets don't know about each other." (Service user 1)

Although staffing was essential to the success of coproduced group, professionals had little or no dedicated time for such projects. In most cases, staff had to find time within their existing workload.

"When I thought of the idea, both the psychologist and the OT thought it was a good idea, but they didn't have any leeway to take it on, they didn't have the space at the time." (Service user 1)

\section{Conclusions and Implications for Practice}

Participants to this project described co-production in community mental health settings as entailing both service users and professionals; co-facilitated groups included a deeper involvement from service users, particularly in the initiation and the planning stages. This chimes with others in the literature [2].

Co-production was seen as generally beneficial for service user co-producers: participants mentioned more particularly improvement in self-esteem, feelings of empowerment and increased sense of purpose. These benefits match well to the meta-themes found by [18] and also relates to Solomon's suggestions [17] about the ways that helping others can improve one's own wellbeing. Co-produced groups provided a stepping stone to initiating or returning to education or to a professional context. Co-production could meet a therapeutic need for the co-producers and enabled them to take an active role in their recovery, helping them to rebuild purpose and agency. There is a tension here: the expectation and endorsement of service users within recovery focused services may lead to an overemphasis of the "significance of personal agency against the responsibility of services to fulfil a duty of care" [16, p. 247].

Taking on too much responsibility was a perceived risk of co-producing; this was acknowledged by staff members who consciously tried to counter excessive pressure. Although addressing the clinical needs of co-producer service users was an important element of the process, this project did not find any undue emphasis or negative impact 
of this on other group participants. Staff felt quite the opposite: having a service user co-producer was seen as more comfortable for other group members, as it allowed for both content and delivery to appropriately reflect service users' experience. Davidson and his colleagues [19] have suggested that patients may benefit from being exposed to people who had recovered to some degree; this was borne out by the present study. Another potential risk of mental health groups is to allow or promote avoidance of normal society [10]; this was not seen as a risk by the participants in our study.

In line with previous studies [11, 12], there were generic benefits to group membership; this included distraction, exercise, shared experience, friendship mood and meaning. It may be that there is a differential benefit for the service user co-producers as compared to the other service users, but the study did not provide data in this area.

Those service users who get involved in co-production may not be representative of other service users in terms of education and pre-existing skill set; it is not really possible to comment in this in a small qualitative study. At least one service user co-producer had literacy problems; not all participants had experience of higher education.

Involvement of both service users and staff were both indispensable to the group outcomes. Staff were able to create boundaries and allowed for the safety of all service users involved; they enabled continuity. The staff allowed service users who would otherwise not have been able to start groups (because of illness or literacy problems) to become involved actively in their own recovery. The service users often had a particular interest or talent in the subject of the group-they were a resource in their own right. The service user led aspect of the groups led to ground rules being more service-user orientated-so people discharged from the care of community mental health teams did not have to leave the groups. In at least one case this had meant that psychotic symptoms in somebody who had been discharged were picked up before crisis point was reached. Specific benefits identified by previous studies $[17,21]$ such as longevity of groups and changing provider attitudes were not addressed by this study.

The groups studied generally necessitated little resources and were cheap to run. Despite this, obtaining the meagre required resources (e.g. room hire) could be difficult; this might be a reflection of the organisation's lack of understanding or expectations from such groups and an over-reliance on service users own initiative and resourcefulness. The groups generally were created following an informal initiation process. It is not clear if a more formal approach-with stronger institutional support-would further promote the development of co-produced groups.
This study has limitations; it did not address the demographics, clinical conditions and diagnoses of those involved in co-production. It may be that those involved do not come from populations that are most difficult to reach [19] and demographics could be a useful avenue of enquiry. The experiences of those service users who were not co-producers were not directly examined in this study; their views are also important and could be included in future research. The groups in the present study generally arose organically. It may be helpful to examine whether it is possible to initiate groups more systematically and also, to take a more longitudinal view of groups. The resourcing of groups is also a major point of interest, especially in the current financial climate.

\section{References}

1. Boyle D, Clark S, Burns S. Hidden work: co-production by people outside paid employment. York: Joseph Rowntree Foundation; 2006

2. Needham C, Carr S. Co-production: an emerging evidence base for adult social care transformation: SCIE Research briefing 31. London: SCIE; 2009.

3. Boyle D, Harris DM. The challenge of co-production: how equal partnerships between professionals and the public are crucial to improving public services. London: NESTA; 2009.

4. Boyle D, Stephens L, Ryan-Collins J. Co-production: a manifesto for growing the core economy. London: New Economics Foundation; 2008.

5. Cahn E. No more throw away people; the co-production imperative. Washington: Essential Books; 2000.

6. Boyle D, Slay J, Stephens L. Public services inside out. London: National Endowment for Science Technology and the Arts; 2010.

7. Thorneycroft J, Dickson M. Books, meaning and hope. Ment Health Pract. 2014;18:14-7.

8. King R, Lloyd C, Meehan T. Handbook of psychosocial rehabilitation. Oxford: Blackwell; 2007.

9. MacInnes DL, Lewis M. The evaluation of a short group programme to reduce self-stigma in people with serious and enduring mental health problems. J Psychiatr Ment Health Nurs. 2008;15:59-65.

10. Corrigan $\mathrm{P}$, et al. Principles and practice of psychiatric rehabilitation. New-York: The Guilford Press; 2009.

11. Mortazavi SS, et al. Comparing the effects of group and homebased physical activity on mental health in the elderly. Int J Prev Med. 2013;4:1282-9.

12. Montgomery P, et al. Stories of women involved in a postpartum depression peer support group. Int $\mathrm{J}$ Ment Health Nurs. 2012;21:524-32.

13. Kennedy M, Humphreys K. Understanding worldview transformation in members of mutual help groups. In: Lavoie $\mathrm{F}$, Borkman $\mathrm{T}$, Gidron B, editors. Self-help and mutual aid groups: international and multicultural perspectives. New-York: Haworth press; 1994. p. 181-98.

14. Pistrang N, Barker C, Humphreys K. Mutual help groups for mental health problems: a review of effectiveness studies. Am J Community Psychol. 2008;42:110-21.

15. Casiday R, et al. Volunteering and health: what impact does it really have? London: Report to Volunteering England; 2008. 
16. Stickley T, Wright N. The British research evidence for recovery, papers published between 2006 and 2009 (inclusive). Part One: a review of the peer-reviewed literature using a systematic approach. J Psychiatr Ment Health Nurs. 2011;18:247-56.

17. Solomon P. Peer support/peer provided services underlying processes, benefits, and critical ingredients. Psychiatr Rehabil J. 2004;27(4):392-401.

18. Salzer MS, Shear SL. Identifying consumer-provider benefits in evaluations of consumer-delivered services. Psychiatr Rehabil J. 2002;25(3):281-8.

19. Davidson L, Chinman M, Kloos B, Weingarten R, Stayner D, Kraemer Tebes J. Peer support among individuals with severe mental illness: a review of the evidence. Clin Psychol: Sci Pract. 1999;6(2):165-87.
20. Topping KJ. Trends in peer learning. Educ Psychol. 2007;25(6):631-45.

21. Salem D, Reieschl TM, Randall KW. The effect of professional partnership on the development of a mutual-help organization. Am J Community Psychol. 2008;42:179-91.

22. McDermott F. Group Work in the mental health field: researching outcome. Aust Soc Work. 2003;56(4):352-63.

23. Braun V, Clarke V. Using thematic analysis in psychology. Qual Res Psychol. 2006;3(2):77-101.

24. Miles MB, Huberman M. Qualitative data analysis: an expanded sourcebook. 2nd ed. Thousand Oaks: Sage; 1994. 